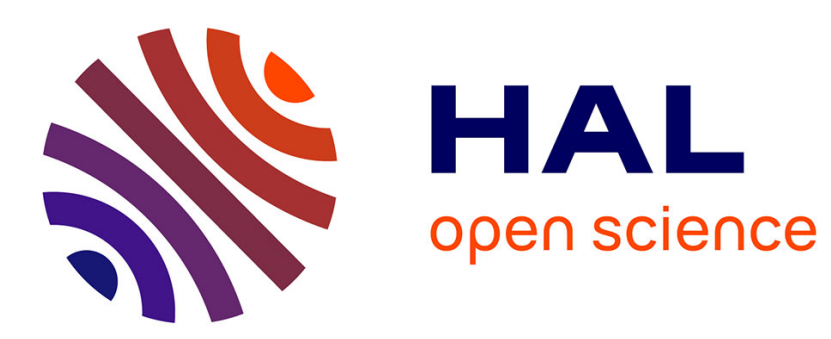

\title{
Columnar growth of ALN by r.f. magnetron sputtering: Role of the $101^{-} 3$ planes
}

\author{
Valerie Brien, P. Miska, B. Bolle, P. Pigeat
}

\section{To cite this version:}

Valerie Brien, P. Miska, B. Bolle, P. Pigeat. Columnar growth of ALN by r.f. magnetron sputtering: Role of the $101^{-} 3$ planes. Journal of Crystal Growth, 2007, 307 (1), pp.245-252. 10.1016/j.jcrysgro.2007.06.013 . hal-02900055

\section{HAL Id: hal-02900055 \\ https://hal.science/hal-02900055}

Submitted on 29 Sep 2020

HAL is a multi-disciplinary open access archive for the deposit and dissemination of scientific research documents, whether they are published or not. The documents may come from teaching and research institutions in France or abroad, or from public or private research centers.
L'archive ouverte pluridisciplinaire HAL, est destinée au dépôt et à la diffusion de documents scientifiques de niveau recherche, publiés ou non, émanant des établissements d'enseignement et de recherche français ou étrangers, des laboratoires publics ou privés. 


\title{
Columnar growth of AIN by r.f. magnetron sputtering: role of the $\{10 \overline{1} 3\}$ planes
}

\author{
V. Brien ${ }^{\mathrm{a}}$, P. Miska ${ }^{\mathrm{b}}$, B.Bolle $^{\mathrm{c}}$, P. Pigeat ${ }^{\mathrm{a}}$
}

a. CNRS, Laboratoire de Physique des Milieux Ionisés et Applications, UMRCNRS 7040,

Université Henri Poincaré Nancy 1, Faculté des Sciences et Techniques, Boulevard des Aiguillettes, B.P. 239, F-54506 Vandoeuvre-lès-Nancy Cedex, France b. Université Henri Poincaré Nancy 1, Laboratoire de Physique des Matériaux, UMRCNRS 7556, Faculté des Sciences et Techniques, Bouleyard des Aiguillettes, B.P. 239, F-54506 Vandoeuvre-lès-Nancy Cedex, France

c. Université Paul Verlaine - Metz, Laboratoire d'Etudes des Textures et d'Applications aux Matériaux, UMRCNRS 7078, ISGMP Bât. B, Ile du Saulcy, F-57045 METZ Cedex 1, France

For correspondence: Valerie.Brien@1pmi.uhp-nancy.fr Tel: + $33(0) 383684928$, Fax: + $33(0) 383684933$

\section{ABSTRACT}

Aluminium Nitride films prepared by radio frequency magnetron reactive sputtering are usually columnar films with a $\{0002\}$ fibre texture. However an original homogeneous nanostructural growth mode was observed in this study. The description of the shape of the grains in combination with crystallographic investigations reveals this growth mode is the result of an oblique growth perpendicularly to the $\{10 \overline{1} 3\}$ planes. Observations performed on feather-like grained films show that the $\{0002\}$ planes grow normally to the substrate and the 
$\{10 \overline{1} 3\}$ planes grow at $32^{\circ}$ away from the normal and perpendicularly to the axis of the branches of the feathers. The growth mode differs from the columnar one only by the shape of the formed grains. The width of the sub-grains ranges from 6 to $24 \mathrm{~nm}$. The observation of this morphology allows us to propose a crystalline growth model of these films and more generally of the classical $\{0002\}$ textured columnar films. The morphologies and microstructures were investigated by scanning electron microscopy, transmission electron microscopy and atomic force microscopy. The crystallographic texture was determined by Xray diffraction pole figure measurement. Chemical study was performed by Auger electron spectroscopy and energy dispersive spectroscopy of X-rays.

${ }^{\text {\#} F o r ~ c o r r e s p o n d e n c e: ~ p l e a s e ~ c o n t a c t ~ V . ~ B r i e n, ~ V a l e r i e . B r i e n @ l p m i . u h p-n a n c y . f r, ~}$ Tel: + 33 (0) 836849 28, Fax: + 33 (0) 383684933

Keywords: A1. Crystal morphology, Nanostructures, Growth models, A3. Physical vapor deposition processes, B1. Aluminium nitride, B2. Piezoelectric materials

PACS classification codes: 81.10.A, 81.15.C, 73.61.J 


\section{Introduction}

AlN, owing to its high electromechanical coupling, its thermal conductivity comparable to copper and its high sound velocity is used in Surface Acoustic Waves (SAW) devices and is currently the subject of much research. In addition, due to a large and direct energy band gap, AlN and $\mathrm{AlN}+\mathrm{X}$ ( $\mathrm{X}$ is a doping atom) could have opto-electronic applications [1,2]. Often used in semiconductor multi-layers as an insulator, this dielectric material also possesses other useful properties such as excellent corrosion resistance, high mechanical strength and a weak thermal expansion coefficient that make it a very attractive material for further applications in micro and nano-systems or sensor technologies.

To enhance the properties mentioned above, the microstructure of AlN has been optimized to yield either single crystals [3-5], or columnar [0002] highly textured films [617].

The decrease in size of the different elements constituting electronic devices requires studies of physical and chemical properties as a function of the nanosizing. In recent years, the study of the nano-scaling of different materials has shown that physical properties can be strongly modified [1], and then exploited for technical applications.

Low dimensional structures of AlN in films can be expected to lead to new materials with new combinations of hopefully enhanced physical properties. For instance, the photoluminescence or optical absorption properties of AlN powders (doped or not) are strongly modified when the AlN grain sizes are reduced down to the nanometer size $[2,18$ 19].

So, low dimensional structures of AIN in films can undoubtedly be expected to produce new materials exhibiting different and hopefully enhanced physical properties. 
The work presented here is part of a project whose goal is to create high-quality nanostructured aluminium nitride films with grain sizes and shapes controlled by wellestablished synthesis protocols [19]. Films were prepared by reactive magnetron sputtering, a common technique used in the microelectronics industry. The films usually prepared with this technique are polycrystalline and exhibit either a mix of orientation or the columnar [0002] texture. Other kinds of structures have been found, and are presented elsewhere. They are amorphous, made of nano-columns, nano-rods or nano-equiaxed particles dispersed in an amorphous matrix. This preliminary work suggested that the correlation between the oxygen content in the samples and the nanostructures had to be specified (for values ranging from few atomic $\%$ to 40 atomic $\%$ ). Special precautions were taken so that the obtained films in the current study contain the lowest possible values of oxygen.

The study of the microstructures and morphologies of the films prepared under specific conditions that will be specified revealed they exhibited special grains. The goal of this article is to show that the apparition of these shapes are not a trivial event and that they allow the understanding of the growth of the classical $\{0002\}$ oriented films. The article also aims to present the detailed characterization of these new nanostructures. The morphology, crystallographic texture and chemical characteristics were studied and are presented here.

The paper will describe the experimental reactive magnetron sputtering set-up that was built for the purpose of this study and specifically for deposition under ultra low background pressures. The experimental procedure will be related. The experimental characterization techniques will be detailed. The morphology of the films was studied by Transmission, Scanning Electron and Atomic Force Microscopies (TEM, SEM and AFM). The crystallographic texture of the films was obtained by four circles X-ray diffraction. Chemical compositions were measured by Energy Dispersive X-ray Spectroscopy (EDXS) 
and Auger Electron Spectroscopy (AES).

\section{Experimental procedure}

\subsection{Synthesis}

The especially designed experimental apparatus consists of a baking UHV (Ultra High Vacuum) chamber using a classical diffusion-pump. A liquid nitrogen-cooling trap is used to absorb water vapour. The obtained background pressure is around $1.10^{-6} \mathrm{~Pa}$ of $\mathrm{H}_{2} \mathrm{O}$ controlled by mass spectroscopy. The chamber is equipped with a radio frequency (13.56 $\mathrm{MHz}$ ) pulsed magnetron sputtering system especially designed to work under UHV conditions delivering the magnetron power $\mathrm{W}(50<\mathrm{W}<300 \mathrm{~W})$. In this study, bias voltage is set to 0 Volt. The target disk is made of pure aluminium (purity of $99.99 \%$ ), its diameter and its thickness are $60 \mathrm{~mm}$ and $3 \mathrm{~mm}$ large respectively and its distance from the sample is set to $150 \mathrm{~mm}$. A gas mixture of Ar and $\mathrm{N}_{2}$ of high purity (99.999\%) is used for sputtering. The percentage $\alpha$ of $\mathrm{N}_{2} /\left(\mathrm{Ar}+\mathrm{N}_{2}\right)$ in the gas mixture is set to $75 \%$. During the treatment, a controlled pumping valve and mass-flow/controllers are used to keep the total sputtering pressure $\mathrm{P}$ constant $(0.2<\mathrm{P}<5 \mathrm{~Pa})$. The flow rates of argon and nitrogen gas are controlled with MKS Mass-Flo Meters (1.5 $\mathrm{sccm} \mathrm{N} \mathrm{N}_{2}, 0.5 \mathrm{sccm}$ Ar) and the total working pressure is measured using a MKS Baratron gauge. Films are deposited on monocrystalline [001] oriented Si wafers. Substrates are cleaned with basic solvents. The last stage of cleaning is an ultrasonic bath in distilled water. The target was systematically sputter cleaned for 15 min using an Ar plasma to remove the native oxide contamination (cleaning conditions: $\mathrm{P}=0.5$ $\mathrm{Pa}, \mathrm{W}=300 \mathrm{~W}$ ). Prior to deposition, the chamber is set into operation with the chosen plasma conditions for $30 \mathrm{~min}$ so that the reactor can reach its thermal equilibrium.

The temperature of the substrate is measured with a thermocouple. It was found that the temperature changes stayed below $50^{\circ} \mathrm{C}$. It was concluded that the heating is only due to the plasma heating. 
The reactor was equipped with an interferential optical reflectometer for real-time control of the thickness and the growth rate of the deposited layer. Global deposition rate $\delta$ of the films is obtained by dividing the final thickness of the layers by the total deposition time.

Different films were prepared taking special precautions so that the film would contain the lowest values of oxygen (very low background vacuum and high purity gases were chosen). The thicknesses of the films were chosen either around $200 \mathrm{~nm}$ to make the TEM observations easier, or around $1 \mu \mathrm{m}$ to test the continuity and homogeneity of the morphology of the films throughout the film.

The samples presented in this study were prepared with pressure $\mathrm{P}$ ranging from 3 to $5 \mathrm{~Pa}$ and power $\mathrm{W}$ ranging from 50 to $100 \mathrm{~W}$, respectively.

\subsection{Techniques of characterization}

Surface and cross-sectional microstructures were observed by SEM and TEM. SEM observations were performed on a Jeol JSM $6500 \mathrm{~F}$ using an accelerating voltage of $5 \mathrm{kV}$. TEM was employed to investigate the nanostructure of the films. TEM observations were carried out on a Philips CM20 microseope operating at an accelerating voltage of $200 \mathrm{kV}$. They were performed on matter chips sampled on the films by the microclivage technique.

The surface of the material was observed using an AFM (D3100, Digital Instrument) in tapping mode with a scanning speed of $1 \mu \mathrm{m} \cdot \mathrm{s}^{-1}$.

Elemental composition of the films was systematically estimated by EDXS or AES. EDSX spectra were recorded by means of an EDAX spectrometer mounted on a CM20 Philips microscope equipped with an ultra thin window X-Ray detector. The analyses were carried out in nanoprobe mode with a probe diameter of $14 \mathrm{~nm}$. AES concentration profiles were recorded by means of a Microlab VG MKII using an Ar etching gun VG microprobe EX05. The sensibility factors of the two techniques were determined using $\mathrm{AlN}$ and $\mathrm{Al}_{2} \mathrm{O}_{3}$ reference samples. 
The preferred orientation of the grains of the film was determined by X-ray diffraction pole figure measurement using the $\mathrm{Cu} \mathrm{K}_{\alpha}$ radiation (four circles X-ray diffraction). The goniometer was equipped with a curve sensitive detector INEL CPS 120 , having a $120^{\circ} 2 \theta$ angular aperture and configured to simultaneously record several pole figures and their background. This method is called multi pole figure measurement [21]. One recalls that a pole figure of type $\{\mathrm{hkl}\}$ represents the angular distribution of intensities of the reflections of this Bragg family on a stereographic projection. Iso-intensity lines were chosen so that the most intense zones appeared on every pole figure. In case of fibre texture, to simplify the presentation of the results, one can also present the radial poles figures (or fibre texture plot or pole diagram) obtained from the pole figures by adding the intensities along the azimuth angle. This presentation gives the variation of the intensity of the diffracting plane versus the tilt (declination) angle. The intensities of the radial pole figures presented were corrected from background, diffracting volume and given in multiple random unit.

\section{Description of the feathery nanostructured films}

\subsection{Cross sectional and surface morphology}

Several films prepared with the previously mentioned experimental conditions (low power, high pressure, long target-substrate distance) exhibited atypical morphology called here "feather-like" structures.

The most explicit example is shown by TEM micrographs presented in Fig.1. The TEM cross view (Fig.1(a)) shows that the film can be separated in three growth zones. The first layer corresponds to a very thin equiaxed nucleation step (few nm) often described as adaptation layer between the AlN films and the substrates. The second layer, which is 150$200 \mathrm{~nm}$ thick, is made of classical conic columns growing perpendicular to the substrate. In the third layer, grains highly oriented with respect to the substrate, exhibiting a feather-like shape can be found. These feathery grains grew in the continuity of the columns of the second 
layer. Higher magnification imaging (Fig.1(b)) shows details of this growth zone allowing a better view of their internal structure and of the oblique growth. It appears they are constituted of oblique branches. The width of branches ranges from 6 to $24 \mathrm{~nm}$. The angle between the branches and the trunk was found to be around $32^{\circ}$, and they are separated by void. Because of the high thickness of the film with respect to electron transparency, no top view could be recorded. Remarkably, the grains do not exhibit any dislocations. Many other samples exhibit the trace of oblique growth. On certain samples these substructures exhibit rough boundaries still separated by void (Fig.1(c)). This roughness can present different degrees: soft or strong. Other samples exhibit parented structures like the geometrical shapes shown (Fig.1(d)). It seems this surface shape is a beginning of the growth of oblique branches. These last two microstructures can be understood as transition microstructures between the initial columnar one and the well marked feathered one, just described above. Detailed observations of classical columnar samples then show many cases of inclined structures as the one typically exemplified in Fig.1(e). Every time, the measurement of the angle between the main axis of the grain and the (more a less rough) branches gives around $32^{\circ}$.

The SEM cross view of the most typical sample is presented in Fig.2(a). It shows that the feathery grains fill the whole volume of the film attesting so of its homogeneity. The random distribution of the heads of the feathers seen on the SEM top view attests that the films are not laterally textured. However the top view recorded by AFM allowed to evidence triple points exhibiting $120^{\circ}$ angles and grains with six sides (cf. Fig.2(b)) suggesting so that three c axis of the AlN structure are normal to the substrate.

\subsection{Crystallographic characterizations}

Crystallographic orientation of the grains was first studied by electron diffraction. The indexation of the electron diffraction pattern corresponding to the feathers presented in Fig.1(b) is presented in Fig.3. Knowing the rotation between the electron image and the 
diffraction, the normal direction $\vec{n}_{0}$ to the substrate could be inserted on the electron diffraction. It not only indicates that the films are strongly textured with direction [0002] perpendicular to the substrate, but also suggests that the planes laying at $32^{\circ}$ away from the normal (mentioned on the figure) are the $\{10 \overline{1} 3\}$ ones, implying that the growth direction of the oblique branches would be perpendicular to the $\{10 \overline{1} 3\}$ planes.

In order to get statistical and complete information, four circles X-ray diffraction was also performed to measure the preferred orientation of the grains constituting the films. Despite the small size of the width of the grains: it was possible to record correct diffractograms. A first check was obviously done looking on the graphs being the sum of all possible recorded intensities versus the Bragg angle; to be sure the films are pure and made of würztite AlN. The as measured $\{0002\},\{10 \overline{1} 1\},\{10 \overline{1} 2\},\{10 \overline{1} 3\},\{11 \overline{2} 2\}$ and $\{20 \overline{2} 1\}$ pole figures were measured, only the $\{0002\},\{10 \overline{1} 1\},\{10 \overline{1} 2\}$ and $\{10 \overline{1} 3\}$ pole figures of the most typical sample are shown here. They are presented in Figs. 4a, b, c and d respectively. Except for the $\{10 \overline{1} 2\}$, all pole figures measured for the sample present the same symmetry around the normal direction of the sample yielding a fibre texture with the normal direction of the film as fibre axis. In other words, this says that the azimuthal crystalline orientation of the grains is randomly oriented. The four fold symmetry observed on the $\{10 \overline{1} 2\}$ pole figure (Fig.4(c)) is artificially due to the proximity of the Bragg angles of the (220) of the monocrystalline Si substrate and the $\{10 \overline{1} 2\}$ and is the result of the four fold symmetry of the substrate. The axis of the fibre is perpendicular to the $\{0002\}$ planes as the Fig.4(a) shows it. The radial poles figures obtained from the pole figures presented here are shown in Fig. 4 helping so the measurement of the angles between the $\{0002\}$ and the other signals. Among the pole figures, the only crystallographic planes to be located at around $32^{\circ}$ away from the (0002) plane are exactly the $\{10 \overline{1} 3\}$ ones again. The maximum of the peak on the $\{10 \overline{1} 3\}$ radial pole figure is indeed centred around $31^{\circ}$ (Fig.4(h). 
The exact angle between the (0002) and the $(10 \overline{1} 3)$ planes is actually $31.65^{\circ}$. In order to be sure, that no other plane can be located at this angle different considerations were done. General crystal growth rules say the growth direction of crystals is a direction perpendicular to dense stacking planes (i.e. low indices planes). Although, TEM and X-ray four circles diffractometry results indicate that the $\{10 \overline{1} 3\}$ planes satisfy the right angle, one can imagine that other dense stacking planes satisfying the extinction rules of the structure factor of AIN (i.e. being then absent of the X-ray or electron diffraction data) could also satisfy the $32^{\circ}$ condition. To be sure of the conclusion, systematic crystallographic considerations were led. Calculation of the angle $\varphi$ between the $(\mathrm{hk}-(\mathrm{h}+\mathrm{k}) \mathrm{l})(0<\mathrm{h}<10,0<\mathrm{k}<10,0<1<10)$ planes and the (0002) plane were done. The planes making an angle of $32(+/-1)^{\circ}$ with (0002) plane are given in table I. One finds only the planes $(12 \overline{3} 8),(1013)$ and $(11 \overline{2} 5)$. The most densely packed plane of the three planes presented is precisely the one that exhibits the closest angle to $32^{\circ}$.

So, all this proves that the crystallographic planes perpendicular to the growth direction of the branches are the $\{10 \overline{1} 3\}$ planes of the AlN structure. This implies the grains grow according to their $\{10 \overline{1} 3\}$ faceted crystal, and that the tip of the top should be the theoretical angle between two $\{10 \overline{1} 3\}$ opposite planes: that is $116^{\circ}$.

To check it, statistical measures of the angle of the heads were performed by AFM.

The height $(h)$ and the base length $(B)$ of a head were measured in a profile extracted from an AFM height picture. The top angle of the head was then deduced by evaluating the top angle of the triangular of height $h$ and base length $B$. With this method, the top angle of the head was overestimated due to the convolution effects between the AFM tip and the surface. We found an average value of about $136^{\circ}\left(+/-6^{\circ}\right)$. This value is indeed different from the expected value, but the reasoning has to take in account the over evaluation of the 
measure. Moreover, the only other possible growth plane is the $\{10 \overline{1} 1\}$ plane. The calculation of the angle the head should adopt in such a case gives $57^{\circ}$. This measured value leads one to unambiguously conclude that the emerging faces are well the $\{10 \overline{1} 3\}$ planes.

This experimental value has to be compared with the expected $116^{\circ}$ (respectively $57^{\circ}$ ) the head would make in the case of oblique growth of $\{10 \overline{1} 3\}$ (respectively $\{10 \overline{1} 1\}$ ) planes.

The surface mean rugosity $(\mathrm{Ra})$ and RMS rugosity $(\mathrm{Rq})$ have also been evaluated thanks to AFM pictures. They are of 6.5 and $8.28 \mathrm{~nm}$ respectively.

\section{Discussion}

Few references to nanostructures of the type encountered here with feather with branches, or dendrite-like can be found in the literature. Indeed, they are not present on the sputter deposition microstructures zone maps built by Movchan et al or Thornton versus the homologous temperature ( $\mathrm{T} / \mathrm{T}_{\mathrm{m}}, \mathrm{T}_{\mathrm{m}}$ being the melting temperature of the deposited material) and where the temperature could be read as the energy of the incident particles [22,23]. Most of the references to such structures, when not resulting from solid-solid or liquid/solid transformations appear in works dealing with chemical vapour deposition techniques (MOCVD [24], Glow Discharged plasma CVD [25], MOVPE [26], CVD [27]...). However they could be found in inorganic films grown by reactive magnetron sputtering [28-30]. They are named feathers, leaves or dendrite-like structures. Since these morphologies are rare, mechanisms of formation are all the more rare, and physical interpretations on the subject differ from one author to another. When obtained by magnetron sputtering, the authors relate their formation to high-pressure conditions: growth of $\mathrm{W}$ (tungsten) or $\mathrm{MoN}$ [29-30] or to suppression of diffusion with growth direction of "branches" consistent with the direction of oblique incident particles [28]. In a (Ti,Si)N structure obtained by arc evaporation, Flink et al. described a growth mode with a rotating lattice related to the presence of an impurity [31]. 
One proposes here to explain the formation mechanism of the structures described in this work. The explanation is described in Fig.5. In the first stage of the growth, nucleation occurs in a classical amorphous adaptation layer (Fig.5(a)). Subsequently the densest planes of the structure: the $\{0002\}$ ones fill normally as they are the quickest planes to develop exactly as columnar structures grow (Fig.5(b)). The columns thicken according to a classical Van der Drift mechanism. The (0002) surfaces are progressively covered; leaving exposed the slowest forming ones. The experimental results show that these planes are the $\{10 \overline{1} 3\}$ ones. The growth of the grains is then laterally limited by the presence of the other grains (Fig.5(b)). The in-plane orientations of these columns are not correlated to each other thereby explaining the AFM and SEM observations (Fig.2). The experimental parameters used: room temperature, low power, high pressure and long substrate-target distance, generate a nondiffusion regime of the adatoms. The crystalline defects present in the structure (vacancy or insertion types) cannot be eliminated by atomic diffusion. The completion of the $\{10 \overline{1} 3\}$ planes (whose projection along b axis is $[\overline{1} \overline{1} \overline{0} 0]$ shown in Fig.5(d)) then continues on the "normal" sites without any surface diffusion. These experimental conditions create a noncollision atom flux regime and the atoms arrive with low energies under a one-direction flux. The atoms arriving vertically onto the surface then stay at the site of impact. The growth of the above sites, combined to zero superficial diffusion, yields a shadowing effect, as described in 1a to 1c zones in the structure zones models proposed by Mahieu et al [32]. This prevents the row from growing further and thereby creates void grain boundaries (Fig.5(e)). Once the void is created, the shadowing and the no diffusion regime causes the formation of oblique branches or plates.

When the c-AlN films are prepared using high deposition rates, high r.f. powers, low pressures, short substrate-target distances and temperatures laying in the 523-573K range, the grains never form the types of structures found in the samples studied here. The diffusion of 
adatoms prevents the formation of directional voids. This detailed study leads us to hypothesise that the uppermost surfaces of the $\{0002\}$ oriented classical columns are constituted by $\{10 \overline{1} 3\}$ planes. As a consequence, whatever the process conditions of AlN preparation, further theoretical descriptions of the growth kinetics of AlN will have to take into consideration the formation of the $\{10 \overline{1} 3\}$ planes.

\section{Conclusions}

This work describes a new AlN nanostructural morphology prepared at room temperature, high pressure, low power and long substrate-target distance: with sputtering species with very low energies.

The morphological and crystallographic descriptions of these special cases allows us to highlight the importance of the $\{10 \overline{1} 3\}$ planes in the kinetics growth of the würtzite AlN. We propose a film formation model based on the hypothesis that the slowest planes to grow are the $\{10 \overline{1} 3\}$ planes.

\section{Acknowledgments:}

The authors would like to thank Drs J. Ghanbaja, D. Genève and B. Assouar for respectively performing the TEM and EDXS, AES and SEM experiments. 


\section{References}

1. S.C. Tjong and Haydn Chen, Mater. Sci. \& Eng. R 45 (2004), p1

2. V. I. Dimitrova, P. G. Van Patten, H. Richardson and M. E. Kordesch, App. Surf. Sci., 175-176, (2001) p 480

3. G. Bu, D. Ciplys, M. Shur, L.J. Schowalter, S. Schujman and R. Gaska, Electronic Lett. 39(9) (2003), p755

4. K. Okamoto, S. Inoue, N. Matsuki, T.W. Kim, H. Fujioka and M. Oshima, Phys. Stat. Sol. A. Appl. Research, 202 (14) (2005), pR149

5. B. Raghothamachar, B. Jie, M. Dudley, R. Dalmau, Z. Dejin, Z Herro, R. Schlesser, Z. Sitar, W. Buguo, M. Callahan, K. Rakes, P. Konkapaka and M. Spencer, J. Cryst. Growth, 287(2) (2006), p349

6. I. Ivanov, L. Hultm, K. Järrendahl, P. Mäterbsson, J.-E. Sundgren, B. Hjörvarsson and J.E. Greene, J. Appl. Phys. 78 (1995), p5721

7. M. Akiyama, T. Harada, C. N. Xu, K. Nonaka and T. Watanabe, Thin Solid Films 350 (1999), p85

8. H.Y. Joo, H.J. Kim, S.J. Kim and S.Y. Kim, Thin Solid Films, 368 (2000), p67

9. J. H. Choi, J.Y. Lee and J.H. Kim, Thin Solid Films 384 (2001), p166

10. B.H. Hwang, C.S. Chen, H.Y. Lu and T.C. Hsu, Mat. Sci. and Eng. A 325 (2002), p380

11. H. Cheng, Y. Sun and P. Hing, Surf. Coat. \& Tech., 166 (2003), p231

12. A.K. Chu,C.H. Chao, F.Z. Lee and H.L. Huang, Thin Solid Films, 429 (2003), p1 
13. M.B. Assouar, M. El Hakiki, O. Elmazria, P. Alnot and C. Tiusan, Diamond \& Rel. Mater. 13 (2004), p1111

14. M.A. Auger, L. Vazquez, M. Jergel and J.M. Sanchez, Surf. Coat. \& Tech., 180-181 (2004), p140

15. C.K. Lee, S. Cochran, A. Abrar, K.J. Kirk and F. Placido, Ultrasonics 42 (2004), p485

16. J.-X. Zhang, Y. Z. Chen, H. Cheng, L. Uddin, Shu Yuan, K. Pita and T.G. Andersson, Thin Solid Films, 471 (2005), p336

17. W.-J. Liu, S.-J. Wu, C-M Chen, Y.-C. Lai and C.-H. Chuang, J. Cryst. Growth $276(2005), \mathrm{p} 525$

18. A. Olszyna, J. Siwiec, D. Dwiliński, M. Kamińsak, J. Konwerska-Hrabowsak and A. Sokołowska, Mat. Sci. \& Eng., B50 (1997), p170

19. T. Xie, X.Y. Yuan, Y. Lin, X.X. Xu, G.W. Meng and L.D. Zhang, J. Physics Condensed Matter, 16 (9) (2004), p1639

20. V. Brien and P. Pigeat, J. of Cryst. Growth, (2006), under press, doi: 10.1016/j.jcrysgro.2006.10.238

21. J.J. Heizmann and C. Laruelle, J. Appl. Cryst. (1986) 19(6), p467

22. B.A. Movchan and A.V. Demchishin, Fiz. Metal. Metalloved., 28, 4, 653-660 (1969), p83

23. J.A. Thornton, J. Vac. Sci. Technol., 11 (1974), p666

24. U. Backman, A. Auvinen and J.K. Jokiniemi, Surf. \& Coat. Tech., 192(1) (2005), p81

25. H. Saitoh, J. Satoh, T. Ishiguro, K. Kamata and Y. Ichinose, Nippon Kinzoku Gakkaishi 1952, 60(5) (1996), p476 
26. J.P. André, H. Alaoui, A. Deswarte, Y. Zheng, J.F. Petroff, X. Walalrt and J.P. Nys, J. of cryst. growth, 144 (1-2) (1994), p29

27. M. Aizawa, C. Kobayashi, H. Yamane and T. Hirai, Nippon Seramikkusu Kyokai gakujutsu ronbunshi, 101 (3) (1993), p291

28. M. Hiramoto, N. Matsukawa, H. Sakakima, Y. Ichikawa and K. Ijima, J. Appl. Phys., 83 (11) 1998,, p6655

29. Y.G. Shen, Y.W. Mai, Q.C. Zhang, D.R. Mckenzie, W.D. Mcfall and W.E. Mcbride, J. Appl. Phys., 87(1) (2000), p177

30. Y.G. Shen, Mat. Sci. Forum, 490-491, (2005), p589

31. A. Flink, T. Larsson, J. Sjölén, L. Karlsson and L. Hultman, Surf. \& Coat. Tech. 200 (1) (2005), p1535

32. S. Mahieu, P. Ghekiere, D. Depla, R. de Gryse, O.I. Lebedev and G. Van Tendeloo, J. of Cryst. Growth, 290, (2006), p272 


\section{List of figures and tables captions:}

Fig.1: TEM micrographs. a) Dark field image showing the overall cross section of a sample exhibiting the feathered nanostructure. Sample preparation parameters: $\mathrm{W}=100 \mathrm{~W}$, $\mathrm{p}$ = 3.8 Pa. b) Bright field image, detail of Fig.a): Feather or dendrite-like nanostructure of the grains. c) Bright field image. Rough branches of the feather like nanostructure. Sample preparation parameters: $\mathrm{W}=50 \mathrm{~W}, \mathrm{p}=3.9 \mathrm{~Pa}$. d) Parented structures to the feathered one: transition microstructures between the columnar one and the well marked feathered one.Sample preparation parameters: $\mathrm{W}=100 \mathrm{~W}, \mathrm{p}=5.07 \mathrm{~Pa}$. e) Dark field image. Occurrence of oblique growth inside classical columnar films. Sample preparation parameters: $\mathrm{W}=50 \mathrm{~W}, \mathrm{p}=16 \mathrm{~Pa}$.

Fig.2: a) SEM cross view b) Top view AFM derivative picture. Sample preparation parameters: $\mathrm{W}=100 \mathrm{~W}, \mathrm{p}=3.8 \mathrm{~Pa}$. Black arrows indicate grain boundaries with typical $120^{\circ}$ angle characteristic of hexagonal structures with $\mathrm{c}$ axes normal to the surface.

Fig.3: TEM selected area diffraction pattern recorded on the zone presented in Fig. 1b. $\vec{n}$ is the normal to the substrate. Indexation was performed using the AlN würztite structure. Sample preparation parameters: $\mathrm{W}=100 \mathrm{~W}, \mathrm{p}=3.8 \mathrm{~Pa}$.

Fig.4: Four circles diffractometry results. a) b) c) d): pole figures of $\{0002\}$, $\{10 \overline{1} 1\},\{10 \overline{1} 2\},\{10 \overline{1} 3\}$ respectively. e) f) g) h): radial pole figures of $\{0002\},\{10 \overline{1} 1\}$, 
$\{10 \overline{1} 2\},\{10 \overline{1} 3\}$ respectively. Intensities are given in multiple of random unit (mru). Sample preparation parameters: $\mathrm{W}=100 \mathrm{~W}, \mathrm{p}=3.8 \mathrm{~Pa}$.

Fig.5: Proposed growth model. a) Initial step of growth: nucleation in amorphous matter. b) Van der Drift classical growth with a quicker completion of $\{0002\}$ planes than the $\{10 \overline{1} 3\}$ ones c) the presence of defects combined to a no diffusion regime of adatoms provoke shadowing effects, leading to the generation of branches d) left: projection along [01 $\overline{1} 0]$ of the crystalline structure of AlN showing the cut of the (10 $\overline{1} 3)$ plane, right: semihead of a feather, TEM bright field micrograph. $\vec{n}_{1}$ is the direction perpendicular to $(10 \overline{1} 3)$. $\vec{n}_{0}$ is perpendicular to (0001). 


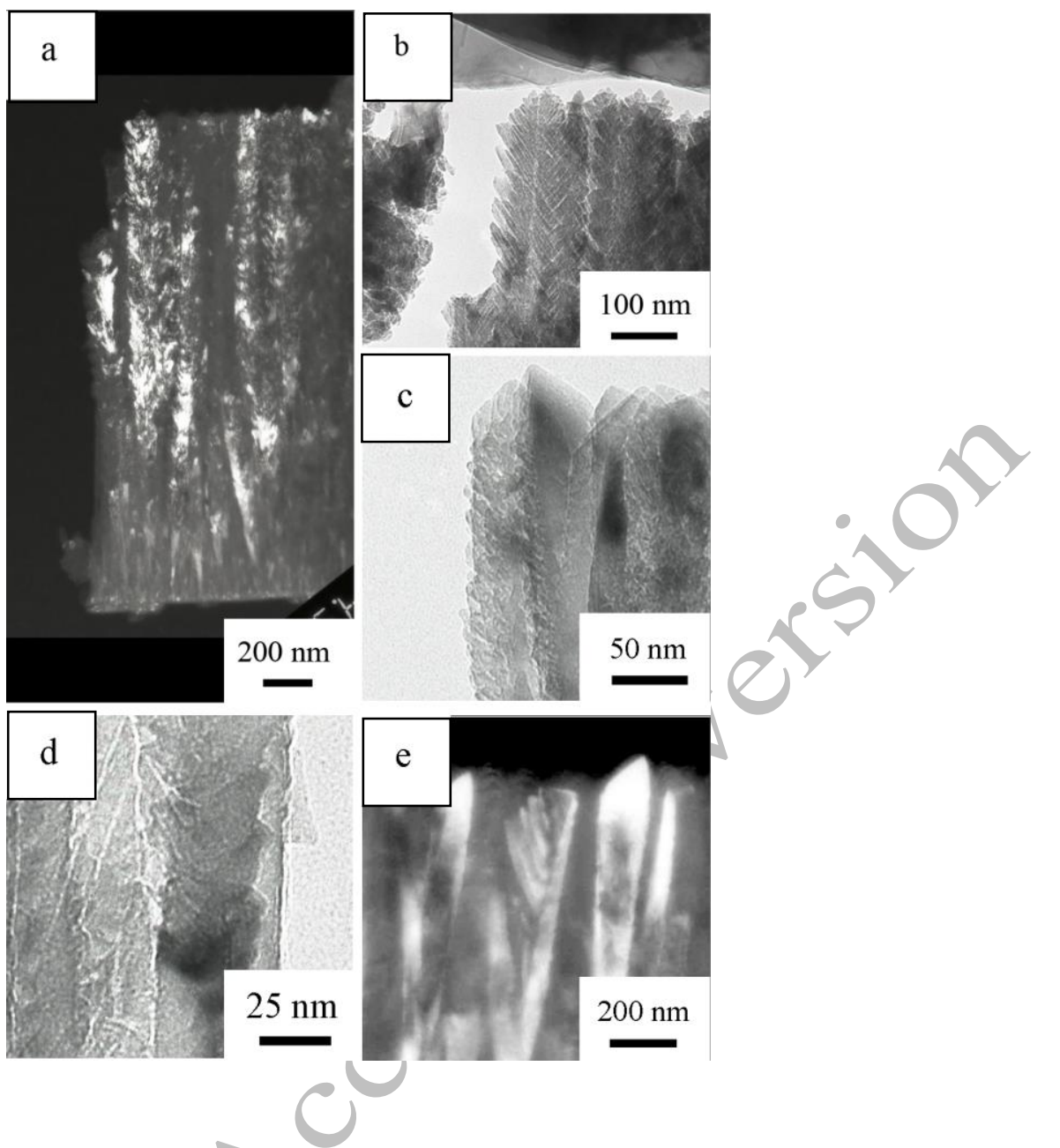

Figure 1 

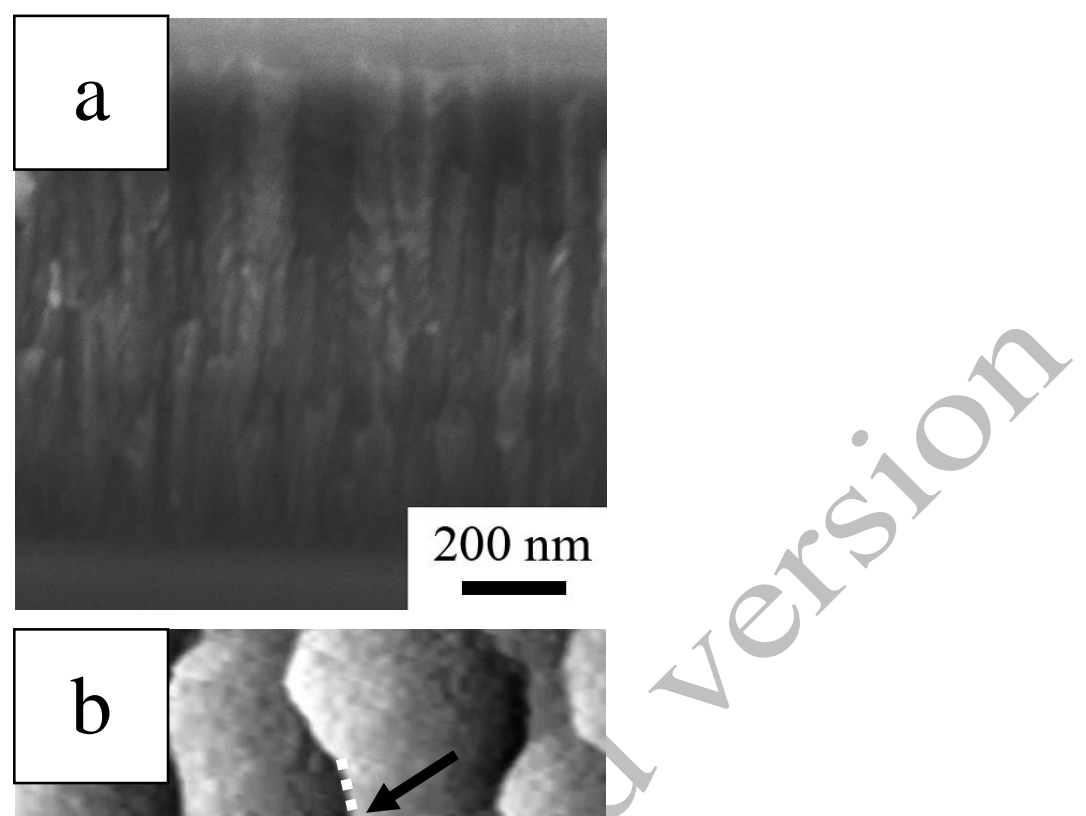

Figure 2

\section{$100 \mathrm{~nm}$}
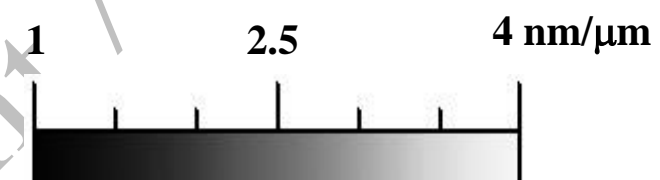


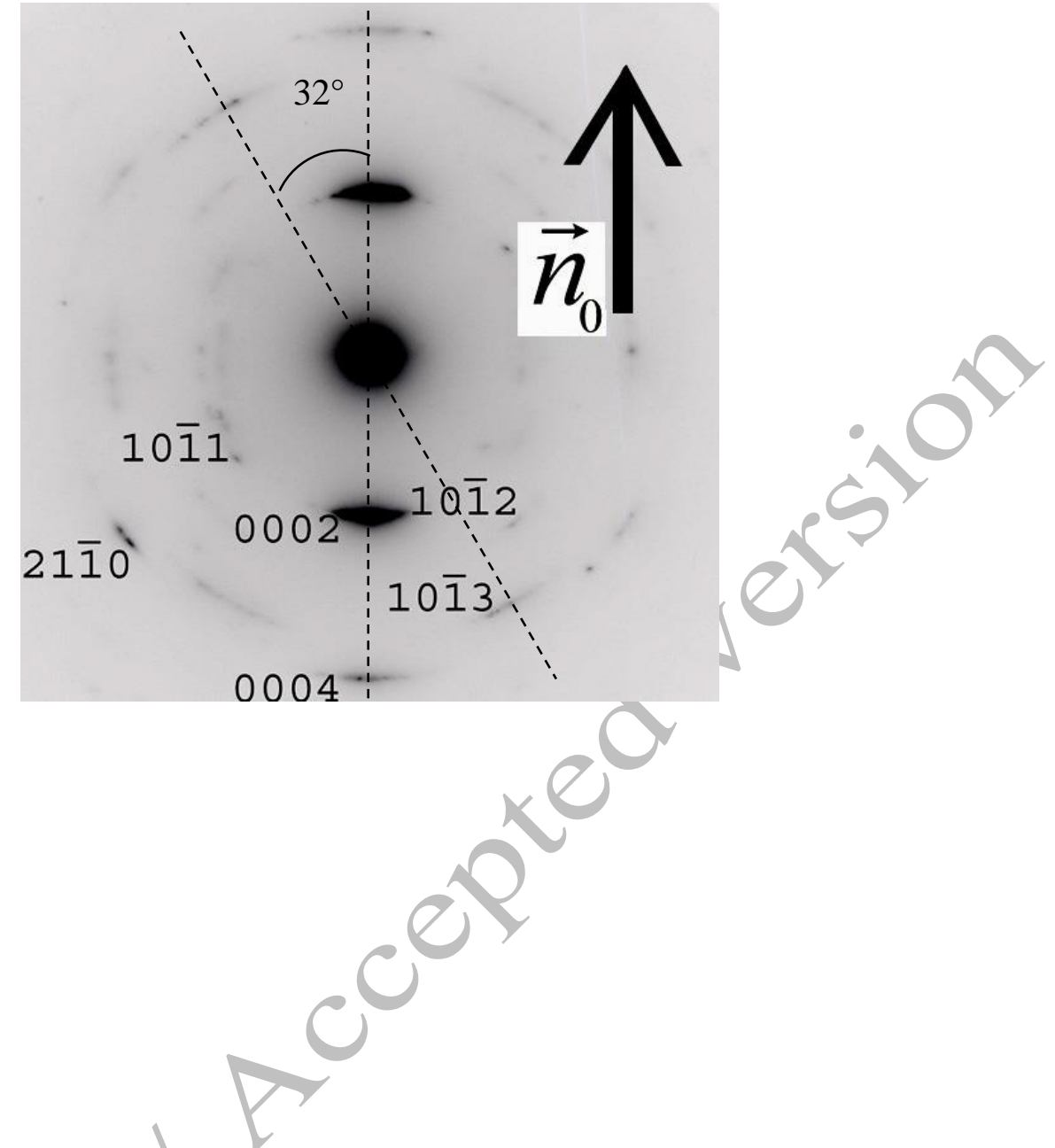

Figure 3 


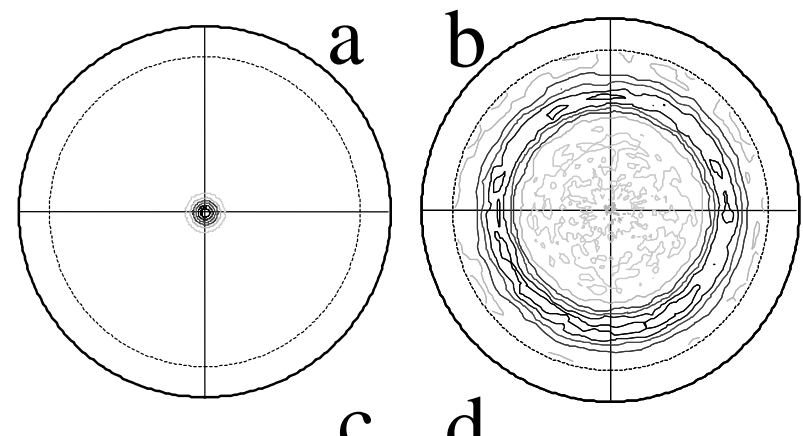

c d
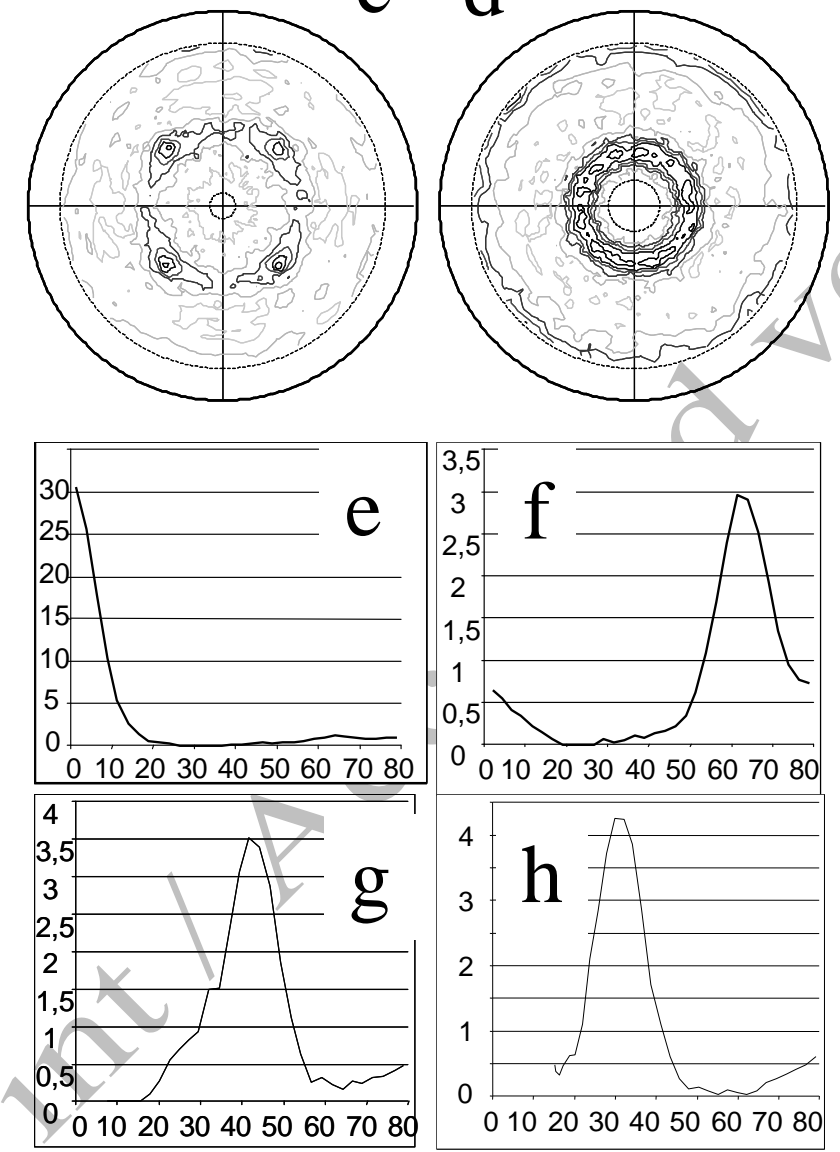

Figure 4 

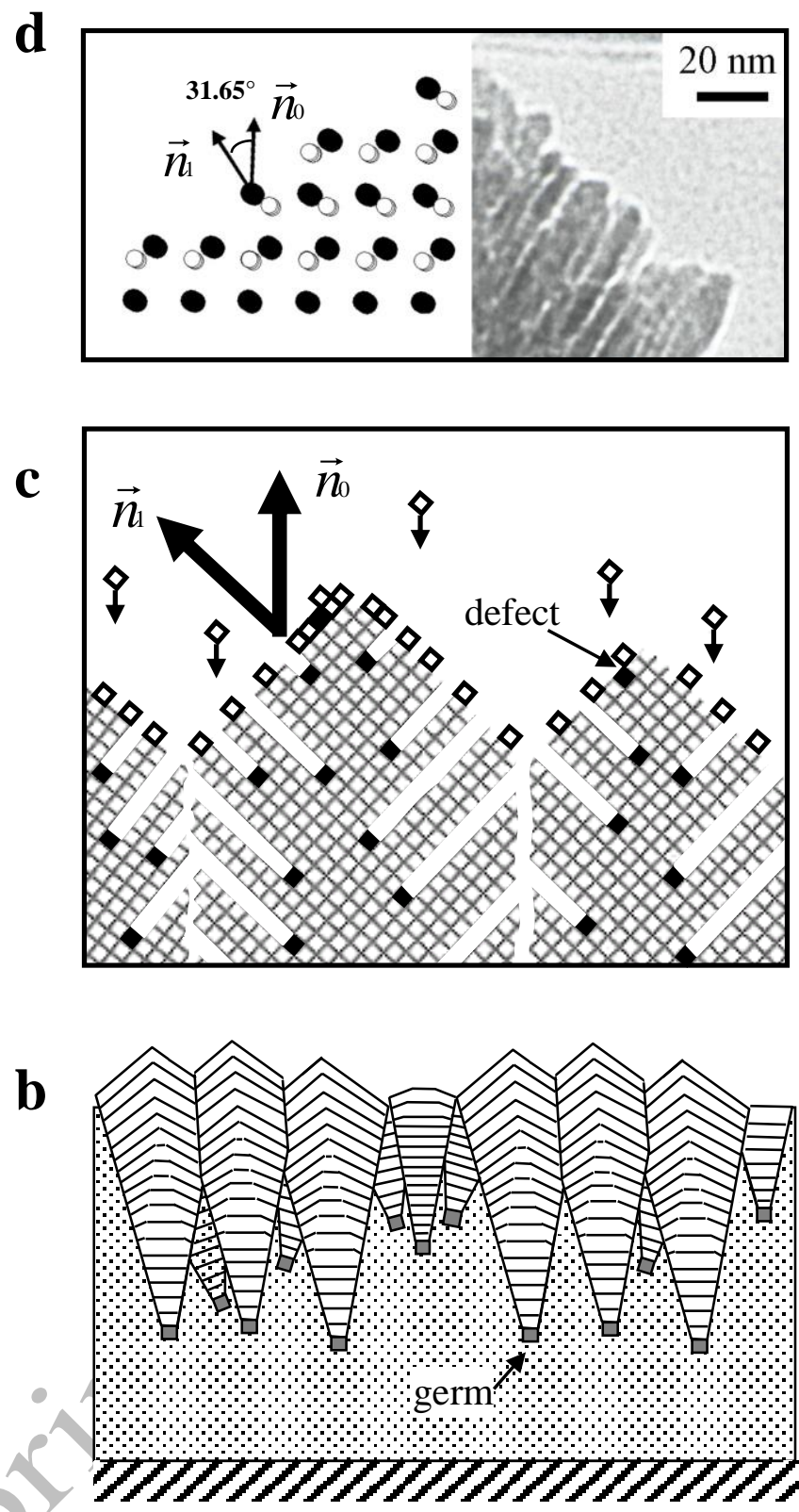

a

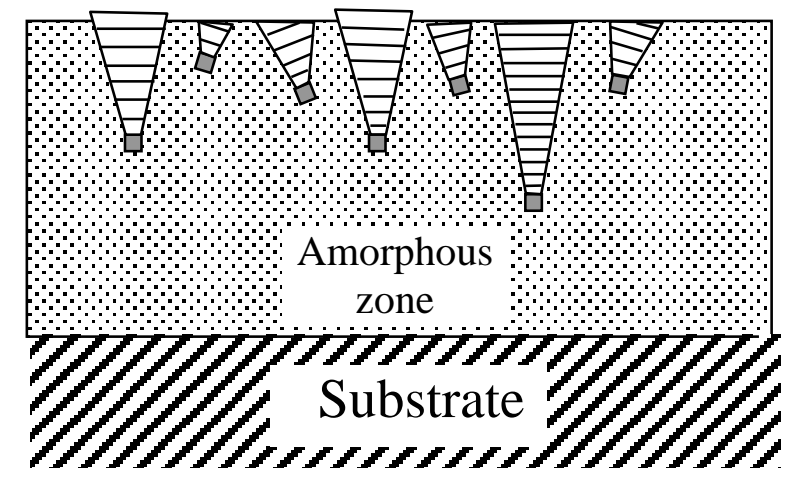

Figure 5 